\title{
Response of Alcoholics to Clinic Treatment
}

\author{
H. J. WALTON,* M.D., M.R.C.P.ED., D.P.M. ; E. B. RITSON, † M.B., CH.B., D.PSYCH. ; R. I. KENNEDY, $\dot{\ddagger}$ M.B., CH.B
}

Brit. med. F., 1966, 2, 1171-1174

Treatment services for alcohol addicts are seriously lacking. The regional hospital boards have been urged repeatedly to provide facilities (Ministry of Health, 1962 ; Scottish Home and Health Department, 1966). The Nuffield Provincial Hospitals Trust sponsored the opening in October 1963 of the Unit for Treatment of Alcoholism at the Royal Edinburgh Hospital. This service is part of the Professorial Unit of the Edinburgh University Department of Psychiatry, and is organized to treat alcoholic patients, to promote research into alcoholism, and to provide experience for professional staff wanting to work in this field.

The first public clinics for treatment of alcoholism were established in Hartford and New Haven in 1944 (McCarthy, 1946). purposely located within the communities they were intended to serve. A survey (Straus and Bacon, 1951) of over 2,000 patients treated in such public clinics disclosed that the great majority were well integrated socially and working responsibly, and were still united with their families. These patients, who came forward voluntarily, did not resemble the stereotyped impression of an alcoholic then current. They realized spontaneously that their addiction required treatment, and availed themselves of services when acceptable clinics were provided.

International emphasis was given to the recommendation that alcoholics should be treated in psychiatric services only if these dealt with acute and recoverable conditions (W.H.O., 1951). General practitioners were shown to be aware of only a small proportion of alcoholics in their practices (Parr, 1957). At the same time as the ineffectiveness of the meagre existing services was emphasized and the extent of undiagnosed alcoholism became evident, the promising treatment-value of group psychotherapy became known (Gliedman, 1958), as did the need for planned aftercare of abstinent alcoholics following initial hospital treatment (Walton, 1961 ; Wolff and Holland, 1964). In the defective state of present knowledge, therapeutic services can be regarded as adequate only when provision has also been made to evaluate the outcome of treatment of alcoholics, to determine the effectiveness of different methods, and to investigate which personal factors affect prognosis.

\section{Plan of Treatment}

The following method of treatment is used in the Edinburgh Unit. Patients are referred by psychiatrists ( $52 \%$ of the sample described below) or by physicians or general practitioners (48\%). Some patients attend spontaneously, but their general practitioners are informed of the self-referral and of the treatment plan proposed.

All alcoholics referred have a detailed psychiatric examination and their addictive state is assessed. Wherever possible they are admitted for initial inpatient treatment lasting three to four weeks. If withdrawal symptoms are prominent these are treated, some patients being kept in bed for the first few days. Any physical illness detected is given appropriate attention.

\footnotetext{
* Senior Lecturer, Department of Psychiatry, University of Edinburgh. † Research Fellow, Unit for Treatment of Alcoholism, Royal Edinburgh Hospital. ‡ Registrar, Royal Edinburgh Hospital.
}

The basis of the treatment is daily group psychotherapy. Spouses are seen and implicated in the treatment programme, the psychiatric social worker and the nursing staff taking a prominent part in co-ordinating the communications between patient and spouse. Patients are helped to understand the course, symptoms, and aetiology of alcoholism by viewing films, by participating with staff in discussions, and by reading about the disorder (Kessel and Walton, 1965). Daily group psychotherapy is combined with individual psychotherapy. The use of disulfiram (Antabuse) is explained and advocated. The psychiatrists and nurses observe the interactions among patients throughout the day, and make full use of these to assist patients in exploring self-defeating behaviour patterns. When any crisis arises nurses call informal group meetings so as to foster the patient's participation and responsibility. Association between inpatients and outpatients is facilitated by providing tea in the unit after outpatient psychotherapy group sessions, the current inpatients acting as hosts.

On discharge an aftercare programme is planned for each patient. Most are assigned in groups of eight to a psychiatrist, who conducts a closed group-therapy session once weekly, lasting one and a half hours. A group is organized to meet for a year or longer. Of the patients discussed in this report, $61 \%$ were assigned to therapy groups; the remaining $39 \%$ were asked to attend for individual interviews as outpatients. Of all patients, $43 \%$ made fewer than six attendances in their first six months of outpatient treatment, while $57 \%$ attended more often.

\section{Patients Studied}

All the first 83 patients referred to the unit after it opened in October 1963 were studied for 18 months after their first attendance. The great majority had been admitted, only $11 \%$ being treated solely as outpatients. A substantial proportion, $24 \%$, were women. The social-class distribution, assessed according to the Registrar-General's classification, is shown in Table I. If it be assumed that alcohol addiction is equally prevalent in all social classes, the figures support our clinical

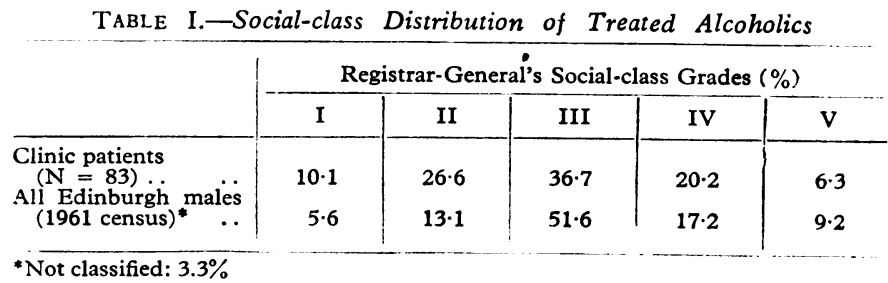

impression that a relative excess of class I and II patients attend the unit, while classes III and V are underrepresented. As a group these patients were less privileged socially than a sample reported from an English unit (Glatt, 1959), where half the male patients belonged to classes I and II, a preponderance thought to be due to the many referrals to the clinic from Alcoholics Anonymous.

A quarter of the patients were in their thirties, a third in their forties, and a quarter in their fifties (Table II). Nearly all were 
Scots; only four were English, and one came from outside Britain.

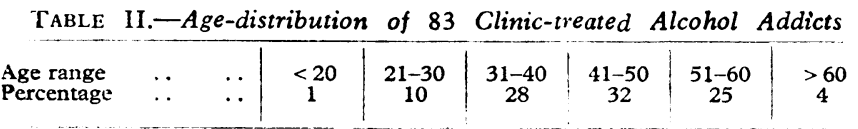

For a substantial number of patients this was not their first treatment venture: $32 \%$ had been treated elsewhere as inpatients for alcoholism and $35 \%$ had attended Alcoholics Anonymous before their referral to the clinic.

Patients were systematically studied for symptoms characteristic of alcohol addiction: $65 \%$ reported alcoholic amnesias and $64 \%$ had experienced symptoms of the abstinence syndrome. Serious social consequences of addiction were also studied: $30 \%$ had at some time been discharged from their occupation on account of excessive drinking, drunkenness at work, or absence due to drinking. Because $40 \%$ of Edinburgh males attempting suicide had been reported to suffer from alcohol addiction (McCulloch, 1965), suicidal behaviour was inquired into. Among the group of patients, $24 \%$ had attempted suicide once or more. Traffic offences due to drinking were reported by $17 \%$. Apart from a traffic offence, conviction for drunkenness was also reported by $17 \%$; for stealing or embezzlement by $14 \%$; and for the use of cheap wine or spirits by $11 \%$.

Alcohol addiction passes into the more serious stage of chronic alcoholism when somatic impairment attributable to alcohol occurs. Physical complications from alcohol consumption, persisting when the intake stopped, were found in $16 \%$. This load of sometimes serious physical illness in a unit for alcoholism makes provision of competent general medical care essential. Six of the patients had delirium tremens, two hepatic cirrhosis (confirmed by liver biopsy), three peripheral neuritis, and two chronic amnesic brain syndrome.

\section{Progress with Treatment}

All patients in the sample were contacted six months after referral and again at 18 months. The examining psychiatrist rated each patient's state at follow-up and also took into account information available from general practitioners, relatives, nursing staff, fellow-patients, outpatient attendance records, and reports of outpatient group conductors.

The drinking status of patients six months after they entered treatment is shown in Table III. Contact was made with all but four patients. Over half $(54 \%)$ were abstinent, and more than half $(30 \%$ of the total) had not taken any alcohol. Some of the abstinent patients had experienced one lapse $(12 \%$ of

\begin{tabular}{l}
\multicolumn{1}{l}{ TABLE III.-Outcome of 83 Treated Alcohol Addicts } \\
\hline \\
\end{tabular}

the total sample), and the same number had had two or three lapses. A lapse was defined as drinking by a previously abstinent alcoholic that did not continue for as long as a week.

Patients known to have lapsed on more than three occasions, even if found abstinent at the follow-up evaluation, were assigned to the next category: improved but drinking. The drinking patients whose consumption was conspicuously less in degree were also rated as improved but drinking ; we required more evidence of diminished consumption than the patients' self-assessment-checking from the reports provided by a spouse, general practitioner, or group psychiatrist. Eighteen per cent. were improved but drinking. Because rating of improvement was more ambiguous than the other assessments, the three raters had to agree ; if they disagreed the patient was included in the next category. This comprised the patients who had not improved ( $23 \%$ of the sample). Some of these persisted doggedly in their clinic attendance in spite of not deriving benefit, and their considerable and repeated demands for support created difficulties for the treatment staff.

The patients who had not been admitted were nine in number $(11 \%)$. As stated above, initial inpatient treatment is regarded as desirable, so the course of these patients is of interest. Three were fully abstinent after six months, one had two lapses but was abstinent, two were improved but drinking, and one was not improved. Progress of alcoholics who were treated solely as outpatients has been the subject of further study (Ritson, 1966).

\section{Outcome After 18 Months}

Other investigators (Davies et al., 1956 ; Gerard and Saenger, 1959) have found that the drinking status of a patient six months after beginning treatment was a good indicator of his state also at two years. This sample of patients was evaluated again 18 months after beginning treatment.

As Table III shows, the proportion found abstinent was similar, $51 \%$. However, by this time almost two-thirds of the abstinent patients had lapsed-that is, they had one, two, or three drinking episodes.

A patient who drank on more than three occasions during the 18 months was rated as drinking even if abstinent at the time of follow-up assessment. Seventeen per cent. of the patients were rated as improved but drinking, on the same criteria as at the six-month follow-up. Twenty-six per cent. were not improved. These proportions were similar to those that had obtained a year previously; but now three of the patients were dead, two by suicide.

The main conclusion to be drawn from these findings is that a majority of abstinent alcoholics occasionally drink. Many set store by daily disulfiram during the initial months of sobriety but give up the self-medication once abstinence is well established. A number hopefully deceive themselves into believing that a capacity for controlled use of alcohol will have returned, and succumb after trial drinking. While some addicts escape serious consequences after drinking once or only a few times, the loss-of-control type of addict (see below) in particular can be precipitated into a calamitous relapse by what he imagines will be a single drink. An outpatient psychotherapy group can explore effectively for a drinking member the conflicts that precipitated his lapse (Gliedman, 1958).

\section{Associated Psychiatric Diagnosis}

While psychiatrists are conscious of the relative unreliability of diagnostic categories of mental disorder, the evaluation of accompanying mental illness in patients can be indicated best in terms of the currently used clinical classification. To classify patients diagnostically, the three authors defined varying categories of disorder and assigned patients by consensus following discussion. We were closely familiar with the patients, and had at our disposal detailed notes about the mental state of each of them at referral, and also on-going observations made during the inpatient phase of treatment.

Alcohol addiction has long been viewed as a symptom of underlying psychiatric illness. This was the sense of Bonhoeffer's (1901) dictum: "Alcohol addiction is in the first place the symptom of a mental disease." Recognizing the 
association of alcoholism and psychiatric disorder, some writers have stressed that the outcome depends on the basic psychiatric condition, which thus complicates evaluation of the prognosis of addiction. Most clinical studies of alcoholics give particular emphasis to personality disorder-for example, one investigator (Glatt, 1959) categorized his subjects according to whether they were or were not psychopathic.

Three main diagnostic categories were defined: personality disorder, psychoneurosis, and psychosis ; and three degrees of personality disorder were differentiated.

Personality disorder was diagnosed when overt psychiatric symptoms were not present but there was definite disturbance in the individual's patterns of relationship with other people, chiefly abnormal dependency, withdrawal, or hostility. The mild degree of personality disorder was rated as present when the patient was aware of difficulty in associating with others but was able to conceal this fairly adequately in his personal relationships. The moderate degree of personality disorder was diagnosed on the basis of disturbed patterns of personal relationships gross enough to be apparent to others. The severe degree, psychopathy, was abnormal personality so gross that the patient actually harmed his social group through aggressiveness or inadequacy of gross extent.

Psychoneurosis was diagnosed if a patient had a syndrome of anxiety, obsessional behaviour, hysterical somatic symptoms, or depressed mood sufficiently gross to impair work or social capacity.

Psychosis was diagnosed when the patient had definite symptoms of the major mental disorders: irreversible dementia, delusions of persecution, or thought disorder.

The most common diagnosis we made was personality disorder of intermediate degree $(41 \%)$. The mild personality disorders were next most numerous $(25 \%)$. Severe personality disorders (psychopathic states) were relatively uncommon $(17 \%)$. Psychoneuroses affected $13 \%$ of the cohort. Only $4 \%$ of the patients were diagnosed as psychotic (schizophrenia in one and chronic amnesic brain syndrome in two).

Outcome was not clearly related to psychiatric diagnosis. Patients with mild personality disorder tended to fare best. Neurotics did as well as the patients with moderate personality disorder: the belief that addicts with accompanying neurosis respond particularly well to treatment was therefore not supported. Psychopaths did least well. But patients in any diagnostic category could be found abstinent six months later or could not be improved. The psychiatric disorder associated with the alcoholism is not a good prognostic indicator.

\section{Pattern of Drinking}

The recent evidence (Morrison, 1964) that mental hospital admissions for alcoholism are seven times more common among men and five times more common among women in Scotland than in England inevitably calls for comparison of drinking cultures in the two countries. One possibility is that drinking patterns vary.

There are two main patterns of abnormal drinking.

1. The better-known one is loss-of-control addiction, which has been widely publicized in information disseminated about alcoholism (to the neglect of the second drinking pattern) perhaps because it is more prevalent in Anglo-Saxon countries and because Alcoholics Anonymous caters specifically for it. In loss-of-control addiction the alcoholic is repeatedly intoxicated; his drinking is phased in bouts separated by brief attempts at abstinence. Characteristically an addict of this type craves for drink, and has a compulsion to continue drinking whenever he starts. Jellinek (1960) suggested that the withdrawal symptoms are especially pronounced, leading to renewed drinking intended to counteract them, but producing comfort for only a short time. He suggests that the discomfort (craving) returns as soon as the blood-level of alcohol begins to fall, thus postulating a physiological basis for the form the addiction takes. The loss-of-control (gamma) addict's pattern of consumption leads to disruption of his social relations, his work capacity, and his health. His " benders" may be separated by spells of illness or delirium tremens; he contacts doctors when appealing to be treated for withdrawal symptoms.

2. The lesser-known form of addiction is the regular, restrained pattern, labelled by Jellinek inability-to-abstain (delta) addiction. In this form of addiction the patient can control the amount be drinks on any given occasion, but he needs to drink each day. If circumstances force him to go without drink for even a few days he develops withdrawal symptoms. Because he does not suffer from craving to the same extent, and is therefore able to adjust his degree of intoxication to suit the circumstances, his behaviour does not become disorganized intermittently to make him socially objectionable. This pattern of regulated but steady drinking is prevalent in a wine-producing country like France, where heavy drinking is the rule ("inveterate drinking"). Some of our patients with this form of addiction are coopers in whisky distilleries, or customs-andexcise men who work all day with spirits to hand.

The addictive pattern of the alcoholics in the present sample was evaluated by detailed questioning on referral. In $34 \%$ the drinking pattern was of the more dramatic loss-of-control type, and $22 \%$ met the criteria of the regular, restrained form. If the pattern of drinking was not distinctive, patients were placed in an intermediate category. Of these, $17 \%$ were rated as closer to the loss-of-control form, while $27 \%$ resembled more closely the regular, restrained pattern.

The evidence, therefore, is that the inability-to-abstain type of addiction, while not as common as the well-known loss-ofcontrol type, is found in substantial numbers of our alcoholic patients. An important proportion of alcohol addicts will be overlooked-certainly in a Scots sample-unless this form of addiction is recognized.

The loss-of-control addicts tend to do better with clinic treatment than the regular, restrained addicts, but not so frequently that outcome is related significantly with drinking pattern (Table IV).

TABLE IV.-Relation Between Drinking-pattern and Outcome Six Months After Treatment in 83 Alcohol Addicts

\begin{tabular}{|c|c|c|c|}
\hline & \multicolumn{3}{|c|}{ Drinking-pattern } \\
\hline & $\begin{array}{c}\text { Regular } \\
\text { Restrained }\end{array}$ & Intermediate & Loss-of-contral \\
\hline $\begin{array}{lcc}\text { Abstinent } & \ldots & \ldots \\
\text { Lapsed but abstinent } & \ldots \\
\text { Improved but drinking. } \\
\text { Not improved } & \ldots & \ldots \\
\text { Unknown } & \ldots & \ldots\end{array}$ & $\begin{array}{r}5 \\
5 \\
3 \\
4 \\
-\end{array}$ & $\begin{array}{r}12 \\
5 \\
7 \\
11 \\
2\end{array}$ & $\begin{array}{r}9 \\
10 \\
4 \\
4 \\
2\end{array}$ \\
\hline
\end{tabular}

\section{Self-punitiveness}

In addition to associated psychiatric disorder and pattern of addiction, we have made clinical evaluations of these patients' personality structure. No typical alcoholic personality has been defined in psychological investigations of alcoholism. The clinical impression is that two broad classes of addict occur, differentiated by their conscience-formation. The conscience is the part of the mind made up of a person's moral laws and values. Some alcoholics judge themselves as unsatisfactory and unworthy ; they are low in their self-esteem, and reproach and despise themselves, strenuously attempting to inhibit their impulses, which they perceive as damaging. Other alcoholics are conspicuously free from self-criticism or inhibition, and show little remorse over their own failures or when they cause distress to others. They are impressively carefree and escapist in outlook.

Whether a person has a self-punitive type of conscience on the one hand, or is uncritical and self-indulgent on the other, is held to depend on the relation that existed between the child and his parents. The conscience is an aspect of personality held to derive in large part from parental rewards and inhibitions that become internalized, parents acting to convey to the growing child the rules and standards of their culture. Clinical observation suggests that self-punitive alcoholics often have a 
past history of parental loss, neglect, or cruelty. The escapist alcohol addicts, in contrast, seem often from their own accounts to have been pampered, over-indulged children.

Three personality categories were defined, and after clinical assessment on referral each patient was assigned to the one considered most appropriate:

1. Impunitive patients were those thought to be hedonists, carefree and uninhibited people, not inclined to blame themselves for failures or misdemeanours. They were low in hostility, and certainly did not turn aggressiveness upon themselves.

2. Moderately self-punitive patients were those who expressed remorse for the harm they caused other people, who were self-critical and discussed their failings, and were assessed as low in self-esteem.

3. Grossly self-punitive patients were conspicuous for selfreproach and self-disgust. Some referred to themselves as rubbish, devils, monsters, or outcasts. Women placed in this category sometimes said they were prostitutes or evil. These harshly self-critical patients often roused much concern and attention in other patients and in treatment staff as a result of their castigation of themselves.

TABLE V.-Relation Between Conscience-structure and Outcome After

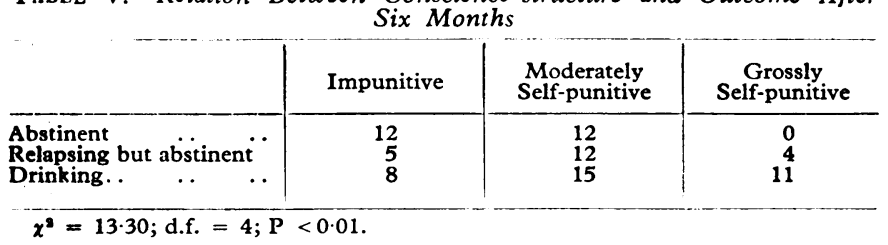

Table $\mathrm{V}$ shows that the alcoholics who did best in treatment (as judged by their drinking status six months after referral) were the moderately self-critical patients. The next most favourable outcome occurred in the impunitive patients (hedonists). Those who responded least well to treatment, not one of them achieving abstinence, were the patients rated as grossly self-critical.

\section{Summary}

Over half the alcohol addicts treated in a specialized clinic were found to be abstinent after six months and also after 18 months. Many of these abstinent patients had episodes of drinking, showing that for them outpatient treatment after the initial hospitalization had been necessary. Although few needed readmission, the number requiring outpatient support increased with the length of the follow-up period.
Outcome was studied in relation to psychiatric diagnosis, pattern of drinking, and conscience-structure. Patients with mild personality disorders responded best in treatment ; patients with psychoneurosis and moderate personality disorder fared equally well, not supporting the belief sometimes advanced that psychoneurotic symptoms in addition to addiction make for particularly good prognosis. Psychopathic addicts did least well.

The regular, restrained form of addiction, not catered for by Alcoholics Anonymous, was the drinking pattern of a substantial proportion of patients, although the more florid loss-ofcontrol form of addiction was the commoner.

Of greater prognostic significance than either the associated psychiatric disorder or the addictive pattern was the patient's conscience-structure. Addicts with moderately self-critical traits did best in treatment ; next most favourable was a conscience of escapist type; none of the grossly self-punitive patients succeeded in becoming abstinent.

\section{REFERENCES}

Bonhoeffer, K. (1901). Die Akuten Geisteskrankheiten der Gewohnheitstrinker. Fischer, Jena.

Davies, D. L., Shepherd, M., and Myers, E. (1956). Quart. F. Stud. Alcohol, 17, 485.

Gerard, D. L., and Saenger, G. (1959). Ibid., 20, 620.

Glatt, M. M. (1959). Lancet, 2, 397.

Gliedman, L. H. (1958). In Problems of Addiction and Habituation, edited by P. H. Hoch and J. Zubin. Grune and Stratton, New York.

Jellinek, E. M. (1960). The Disease Concept of Alcoholism. Hillhouse Press, New Haven.

Kessel, N., and Walton, H. (1965). Alcoholism. Penguin Books, Harmondsworth, Middlesex.

McCarthy, R. G. (1946). Quart. F. Stud. Alcohol, 6, 500.

McCulloch, W. (1965). "Deliberate Self-poisoning or Self-injury." M.Sc. Thesis, University of Edinburgh.

Ministry of Health (1962). Memorandum, H.M. (62) 43. Ministry of Health, London.

Morrison, S. L. (1964). Hlth Bull. (Edinb.), 22, 12.

Parr, D. (1957). Brit. F. Addict., 54, 25.

Ritson, E. B. (1966). M.D. Thesis, submitted to University of Edinburgh.

Scottish Home and Health Department (1966). Alcoholics. Report on Treatment and Rehabilitation. H.M.S.O., Edinburgh.

Straus, R., and Bacon, S. D. (1951). Quart. F. Stud. Alcohol, 12, 231.

Walton, H. (1961). Amer. F. Psychiat., 118, 410.

Wolff, S., and Holland, L. (1964). Quart. f. Stud. Alcohol, 25, 108.

World Health Organization (1951). Techn. Rep. Ser., No. 42. Geneva.

\title{
Erythema Multiforme, Drugs, and Ulcerative Colitis
}

\author{
A. J. CAMERON,* M.B., M.R.C.P. ; J. H. BARON,* D.M., M.R.C.P. ; B. L. PRIESTLEY,* M.B., M.R.C.P., D.C.H.
}

Brit. med. F., 1966, 2, 1174-1178

Erythema multiforme occasionally occurs in patients with ulcerative colitis, and may present in the severe exudative form known as the Stevens-Johnson syndrome. In this paper we describe four such cases. Previous reports of this association are reviewed and also cases in which the Stevens-Johnson syndrome followed the use of drugs for conditions other than colitis. We suggest that erythema multiforme occurring in a patient with ulcerative colitis is usually a complication not of the disease itself but of its treatment with a sulphonamide.

\footnotetext{
- From the Middlesex and Central Middlesex Hospitals, London.
}

A 42-year-old schoolmistress was admitted to hospital on 2 November 1953 with a nine-weeks history of bloody diarrhoea (5 to 10 motions daily), colicky lower abdominal pain, anorexia, and vomiting. Her previous health had been good apart from asthma during adolescence. She was thin, her temperature was $100.4^{\circ} \mathrm{F}$. $\left(38^{\circ} \mathrm{C}\right.$.), and lower abdominal tenderness was noted. Sigmoidoscopy showed a granular proctitis. Haemoglobin was $10.2 \mathrm{~g} . / 100$ ml., W.B.C. 7,600/c.mm., and E.S.R. $50 \mathrm{~mm}$. per hour (Westergren). No pathogens were isolated on stool culture. Changes compatible with mild ulcerative colitis involving the descending and sigmoid colon were seen on barium enema. 